\title{
Ti(II) Oksit Nanoparçacık Yüklenmiş GMA-co-EGDMA Mikroküreler: Tekstil Boyalarının Sulu Ortamdan Fotokatalitik Giderimi
}

\author{
Ti (II) Oxide Nanoparticle Loaded GMA-co-EGDMA \\ Microspheres: Photocatalytic Removal of Textile Dyes from \\ Aqueous Medium
}

\author{
Mustafa Oğuzhan Çağlayan ${ }^{1 *}$
}

Geliş / Received: 01/05/2019

Revize / Revised: 27/08/2019

Kabul / Accepted:29/08/2019

$0^{\circ}$

z- Atık suların arıtılmasında, özellikle tekstil boyalarının sulu ortamdan uzaklaştırılmasında, fotokatalitik teknikler birçok avantaja sahiptir. Bu çalışmada, fotokatalitik aktiviteyi en yüksek seviyeye çıkarmak için, nanoparçacık Ti (II) oksit ( 10 nm) ve hidrojel polimer esaslı heterojen katalizörler üretilmiştir. Elde edilen foto-katalitik malzemenin performansı, sulu ortamlardan reaktif tekstil boyalarının giderilmesi işleminde değerlendirilmiştir. Düşük miktarlarda bile çevre ve insan sağlığına etkisi olan reaktif tekstil boyaları arasından model olarak seçilen alizarin kırmızısı S, Kongo kırmızısı, metilen turuncusu ve asit mavisi için Ti(II) oksit nanoparçacıklar doğrudan kullanıldığında (20 ppm boya, $10 \mathrm{ppm}$ katalizör, 60 dakika ve $25^{\circ} \mathrm{C}^{\prime}$ ta $) \% 92.5$ 'a varan bozunma elde edilirken, mikrokürelere yüklenmiş nanoparçacıklar ile \%71.2 bozunma elde edilmiştir. Ancak, katalizörün ortamdan alınması dikkate alındığında, belirtilen performans azalması önemli değildir. Reaksiyon ortamının ölçeklendirilmesi ile yüksek giderim performansı elde edilebilir.

Anahtar Kelimeler- Heterojen Fotokatalizörler, Polimer Esaslı Taşıyıcı, Nanoparçacık, İmmobilizasyon, Tekstil Boyası Artıma

\begin{abstract}
$A$
bstract- It is known that photocatalytic techniques have advantages over other conventional treatment techniques. In this study, nanoparticle Ti (II) oxide ( $10 \mathrm{~nm})$ and hydrogel polymer based heterogeneous catalysts were produced to maximize photo-catalytic activity. The performance of the obtained photocatalytic material was evaluated in the process of removing reactive textile dyes from aqueous media. When the Ti (II) oxide nanoparticles were used directly for representative reactive textile dyes, alizarin red $\mathrm{S}$, Congo red, methylene orange and acid blue $\left(20 \mathrm{ppm}\right.$ dye, $10 \mathrm{ppm}$ catalyst, 60 minutes and $\left.25^{\circ} \mathrm{C}\right)$ which are extremely hazardous for human and environmental health even at low concentrations, up to $92.5 \%$ decomposition was achieved, while $\mathbf{7 1 . 2 \%}$ decomposition was obtained with $\mathrm{Ti}$ (II) oxide nanoparticle embedded microparticles. However, given the advantages of removing the catalyst, the indicated performance reduction is not critical. By scaling the reaction conditions, high removal performance can be achieved.
\end{abstract}

Keywords- Heterogeneous Photocatalyst, Polymer Based Carriers, Nanoparticle, Immobilization, Textile Dye Treatment

\footnotetext{
1* Sorumlu yazar iletişim: oguzhan.caglayan@bilecik.edu.tr (https://orcid.org/0000-0002-7265-1094) Bilecik Şeyh Edebali Üniversitesi, Mühendislik Fakültesi, Biyomedikal Mühendisliği Bölümü, Bilecik
} 


\section{GİRIŞ}

Çeşitli endüstrilerden kaynaklanan sıvı atıklar alıcı ortamlarda ani ve ciddi zararlara neden olmaktadır [1]. Boya içeren deşarjlar ise mikroorganizmalar, hayvanlar ve insanlar açısından zararlıdır [2]. Dünya boya üretiminin \%1 ila \%20'si arasında bir miktarın, boyama işlemi sırasında tekstil atığı olarak çevreye salındığı düşünülmektedir [3]. Bu atık sular ayrıca, bulundukları ortamda meydana gelen oksidasyon ve hidroliz gibi reaksiyonlar nedeniyle tehlikeli ara ve yan ürünlerin de kaynağıdır [4].

Geleneksel fiziksel teknikler (örneğin aktif karbon üzerine adsorpsiyon, ultrafiltrasyon, ters ozmos, kimyasal ajanlar kullanarak koagülasyon, sentetik adsorplayıcı reçineler üzerine adsorpsiyon vb.) boya türü kirleticilerin uzaklaştırılmasında kullanılmaktadır [5]. Ancak bu yöntemler bir fazdan diğerine kirleticinin aktarılmasını sağlar ve bu nedenle de ikincil kirliliğe neden olur. Bu ikinci faza aktarma durumu da katı atıkların temizlenmesi ve adsorplayıcı maddelerin de geri kazanılması zorunluluğunu ortaya çıkarmaktadır.

Ti(II) oksit, fotokatalizör teknolojisinde ilgi çeken bir malzemedir. Ti(II) oksit, $300 \mathrm{~nm}$ ila $390 \mathrm{~nm}$ arasındaki foton enerjisinde en aktif katalizördür ve $\mathrm{CdS}$ veya $\mathrm{GaP}$ gibi fotokatalizörler toksik ürünlere bozunurlarken Ti(II) oksit birçok katalitik döngü sırasında hala stabildir [6]. Ti(II) oksit, ayrıca kimyasal ve isıl kararlılığ1 veya kimyasal olarak bozunmaya karşı mukavemeti ve güçlü mekanik özellikleri dolayısıyla da fotokatalitik su arıtımında tercih edilmektedir. Belirtilen özellikleri karşılayan Ti(II) oksit fotokatalizör halen bir dizi teknik sorun ile karşı karşıyadır. Bu sorunlardan birisi bir endüstriyel proseste kullanım sırasında yarı iletken Ti(II) oksit katalizörün, su arıtımının ardından ortamdan ayrıştırılmasıdır. Ti(II) oksit parçacıkların küçük olması ve yüksek yüzey alanına sahip olması nedeniyle aglomerasyona olan yatkınlı̆ı da önemlidir. $\mathrm{Bu}$ tür bir aglomerasyon, partikül boyutunun sürekliliğinin sağlanmasında ve etkin yüzey alanının sürekli kullanılabilmesinin sağlanmasında oldukça önemlidir.

Fiziksel ve kimyasal özellik açısından Ti(II) oksit nanoparçacıklar yüksek fotokatalitik özellik gösterse de bu malzemelerin partikül boyutu ve morfolojisi büyük ölçekli su arıtımı için sorun ortaya çıkarmaktadır. Örneğin katalizörün büyük inert bir taban malzemeye bağlanması, hem aktif katalizör site miktarını azaltır hem de aynı zamanda da kütle transfer sınırlamalarını artırır. Ancak fotokatalizörün çamur formunda uygulanması, katalizörün ayrılması için ayrı bir sürecin uygulanmasına neden olur. Ti(II) oksit nanoparçacıklar için destek malzemelerinden birisi gözenekli yapısı nedeniyle doğal killerdir. Literatürde birçok farklı kil destek malzemesi kullanılmışıtır: bentonit [7], sepiolit [8], montmorillonit [9], zeolit [10] ve kaolinit [11]. Günümüzde ise Ti(II) oksit/alumina kompozit membranlar doğrudan fotokatalitik membran olarak kullanılmaktadır [12]. Ti(II) oksit'nin bağlandığı destek malzemesine bir diğer örnek ise polimerlerdir [13]. Ancak düşük fotokatalitik aktivite, membranın yapısal olarak bozulması ve zaman ile membranda biriktirilmiş olan Ti(II) oksidin azalması gibi sorunlar ile karşılaşılmıştır.

Ti(II) oksit malzemelerin fotokatalitik aktivitesinin artırılması yönünde uygulanan temel yaklaşım ise, fotokatalizörün modifiye edilmesi ve fotokatalizöre fotonik aktivasyonu iyileștirecek veya dalga boyunu kaydıracak başka elementlerin veya yapıların ilave edilmesidir. Ti(II) oksit nanoparçacıkların foto cevap aralığını genişletmek için karbon nanotüpler ile kompozit fotokatalizörlerin geliştirilmesi [14], boya şeklinde hassasiyet artırıcılar [15], soy metal veya metal iyonunun yapıya eklenmesi [16], geçiş metallerinin yapiya eklenmesi [17] gibi malzeme mühendisliği yaklaşımları uygulanmıştır. Literatürde genellikle karşılaşılan destek malzemesi cam [18], aktif karbon [19], silika jel [20] ve polimerik malzemelerdir [21]. Ponza taşı, selüloz, paslanmaz çelik, alümina killer, kuartz kumu, zeolitler, monolitler ve fiberler gibi daha az karşılaşılan destek malzemeleri de Ti(II) oksit immobilizasyonu için kullanılmıştır [22]. Silika jeller ve silika-titanyum oksit karışımları, sulu sistemlerde fotokatalizörün, fotokatalitik reaksiyonunun ardından ayrılmasını kolaylaştırmak için fotokatalizör destek malzemesi olarak kullanılmaktadır. Silika destek malzemelerinin gözenekli yapısı, fotokatalitik aktiviteyi ve Ti(II) oksitin performansını artırmaktadır. Silika jeller yüksek yüzey alanı, yüksek ısıl kararlılık ve yüksek oranda sedimentasyon yeteneği sağlamaktadır. Silikaların sağladığı yüksek yüzey alanı, adsorpsiyonu artırarak reaktant için uygun serbest Ti(II) oksit yüzey miktarını da artırmaktadır. Aynı zamanda silika jellerin ışık geçirgen olması, fotonların katalizör yüzeyine erişimini de kolaylaştırmaktadır [23].

Destek malzemesi olarak çok farklı polimerik malzemeler de kullanılmıştır. Polimerik malzemeler arasında polietilen film, polistiren tanecikler, polietilen şişeler, polivinil klorür borular ve polikarbonat plakalar da bulunmaktadır [22]. Polimerik malzemelerin genel avantajı ise kimyasal olarak inert olmaları ve mekanik olarak kararlı olmalarıdır [24].

$\mathrm{Bu}$ çalışmada, glisidil metakrilat-co-etilen glisidil metakrilat (GMA-co-EGDMA) mikrokürelerine yüklenmiş Ti(II) oksit nanoparçacıklar kullanılarak sulu ortamdan reaktif tekstil boyalarının giderim performansı 
incelenmiştir. GMA-co-EGDMA üzerine yüklenmiş Ti(II) oksit nanoparçacıklar ile alizarin kırmızısı S, Kongo kırmızısı, metilen turuncusu ve asit mavisi giderimi ve performans değerlendirmesi hakkında herhangi bir çalışmaya rastlanmamıştır. Bu çalışma, hidrojel karakterdeki mikrokürelere katalizör yüklemesinin, fotokatalitik tepkimelerde performans kayıplarına neden olup olmayacağını belirlemeyi amaçlamaktadır.

\section{MALZEMELER VE YÖNTEM}

Aksi belirtilmedikçe çalışma sırasında kullanılan tüm kimyasal malzemeler analitik saflıktadır ve Sigma-Aldrich veya Alfa Aesar firmalarından temin edilmiştir. Analitik kimyasallar herhangi bir ön saflaştırma gerçekleştirilmeksizin, alındığı haliyle kullanılmıştır. Çözücülerin hazırlanmasında deiyonize su kullanılmıştır. Fotokatalitik bozunma reaksiyonları sıkı-sinterlenmiş (fused) silika camdan imal edilmiş $50 \mathrm{~mL}$ 'lik reaktör içerisinde gerçekleştirilmiştir. Shimadzu UV-1600 spektrofotometre (Japonya), Shimadzu IR-100 FTIR spektrofotometre (Japonya), FEI CTEM geçirgenlik elektron mikroskobu (Amerika), Rikagu Ultima XRD (Japonya) cihazı, Park Systems atomik kuvvet mikroskobu (Kore) cihazları kullanılmıştır.

\section{A. Ti(II) Oksit Nanoparçacıkların Sentezi}

Ti(II) oksit nanoparçacıkların hazırlanması literatürde [25] tarif edildiği şekli ile tetrametil amonyum hidroksit (TMAH) ve titanyum tetraizopropoksit (TTIP) kullanılarak gerçekleşmiştir. TTIP, su içerisine Ti ile $\mathrm{H}_{2} \mathrm{O}$ arasındaki mol oranı 1:50 olacak şekilde ilave edilmiştir. Elde edilen çözelti $15^{\circ} \mathrm{C}$ sıcaklıkta 1 saat süresince karıştırılmıştır. Oluşan çökelek filtrelendikten sonra deiyonize su ile birkaç kez yıkanmıştır. Çökelek, yıkama işleminin ardından TMAH çözeltisine aktarılmıştır. Reaksiyon, kaynama sıcaklığında yoğuşturucu altında 4 saat süresince gerçekleştirilmiştir. Oluşan Ti(II) oksit ürünü süt beyazı kolloid formundadır. Ürün önce santrifüj ile ayrılmış ve ardından birkaç kez mutlak etil alkol ile yıkanmıştır. Kurutma işlemi $200{ }^{\circ} \mathrm{C}$ sıcaklıkta sinterleme işlemi ise $200{ }^{\circ} \mathrm{C}$ ila $650{ }^{\circ} \mathrm{C}$ arasında değiştirilerek, katalitik aktivitenin en yüksek olduğu anataz yapı oluşması için optimizasyon gerçekleştirilmiştir. Literatür verileri 1şığında [26] TTIP/TMAH oranı 60:1, sicaklık yükseldikçe Ti(II) oksit nanoparçacıkların boyutunun arttı̆̆ı bilindiğinden (örneğin $200{ }^{\circ} \mathrm{C}^{\prime}$ ta $9 \mathrm{~nm}$ 'den $650{ }^{\circ} \mathrm{C}$ 'ta 19 nm'ye kadar) $200{ }^{\circ} \mathrm{C}$ 'ta kurutma sıcaklığı tercih edilmiştir.

\section{B. GMA-co-EGDMA Mikrokürelerin Sentezi}

Glisidil metakrilat (GMA) ile etilen glisidil metakrilatın (EGDMA) çapraz bağlayıcı olarak kullanılması ile ortalama çapı $20 \mu \mathrm{m}$ civarında olan mikroküreler üretilmiştir. Başlatıcı olarak $\alpha$ - $\alpha$ '- azoiso-bisbutironitril (AIBN) kullanılmıştır. GMA-co-EGDMA süspansiyon polimerizasyonu tekniği ile $50 \mathrm{~mL} \mathrm{NaCl}$ sulu çözeltisi içerisinde poli(vinilalkolün) (PVA) çekirdek olarak kullanıldığı, azot beslemeli ve yoğuşturucu bağlanmış balonda sentezlenmiştir. Reaksiyon karışımı 30 dakika boyunca karıştırılmış ve başlatıcı ilave edilmeden önce sıcaklık $57^{\circ} \mathrm{C}$ 'a çıkarılmıştır. Kopolimerizasyon işlemi 5 saat süresince $57^{\circ} \mathrm{C}$ sabit sıcaklıkta gerçekleştirilmiştir. 5 saat işlem sonrasında ürün filtrelenmiş, ve etil alkol ve su ile yıkanmıştır. Şekil 1'de polimerizasyon reaksiyonu şematik olarak gösterilmiştir.

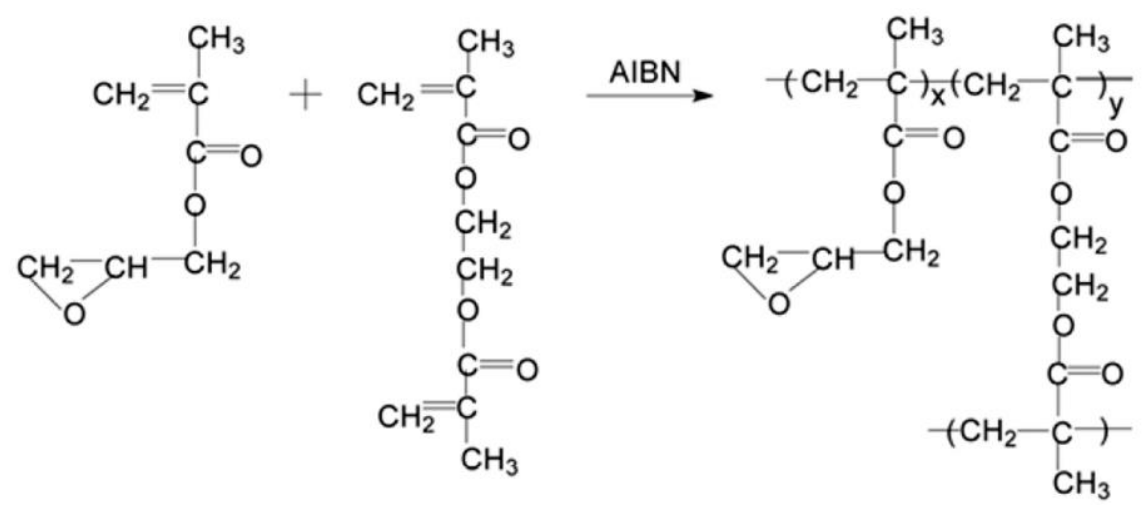

Şekil 1- GMA-EGDMA polimer sentezine ait şematik gösterim 


\section{Ti(II) Oksit Nanoparçacıkların Mikroküre Polimerik Taşıyıcıya İmmobilizasyonu}

Nanoparçacıkların polimerik taşıyıcıya yüklenmesi aşırı şişirilmiş GMA-co-EGDMA hidrojeli içerisinde Ti(II) oksit nanoparçacıkların hapsedilmesi şeklinde gerçekleştirilmiştir. Hapsetme işlemi, farklı derişimlerde nanoparçacık içeren dioksan/deiyonize su içerisine aynı miktarda GMA-co-EGDMA (kütlece \%10 olacak şekilde) ilave edilmesi ve karanlıkta 12 saat sürekli karıştırılması ile elde edilmiştir. Hapsetme işlemi, çözeltinin buharlaştırılması ile tamamlanmıştır.

\section{SONUÇLAR VE TARTIŞMA}

\section{A. Ti(II) Oksit Nanoparçacıkların Karakterizasyonu}

Üretilen Ti(II) oksit nanoparçıkların farklı yöntemler ile elde edilen numunelerine ait XRD sonuçları ile AFM topografi ölçümleri ve TEM grafisi Şekil 2'de verilmiştir. Çalışma sırasında farklı yöntemler kullanılarak üretilmiş olan 3 çeşit Ti(II) oksit nanoparçacık için XRD sonuçları Şekil 2a'da görülmektedir. Kullanılan iki yöntemde anataz fazının yanı sıra rutil fazı ve hatta brokit fazı elde edilmiştir. Literatürde belirtildiği şekli ile fotokatalitik aktivite açısından en önemli sonuçlar anataz fazına sahip Ti(II) oksit kullanılarak elde edildiği için [26], çalışmada yalnızca anataz fazının en yüksek elde edildiği yöntem ile üretilen ve $200{ }^{\circ} \mathrm{C}$ 'ta kurutulmuş olan örnekler kullanılmıştır.

Ti(II) oksit nanoparçacıklara ait TEM görüntülerinden yaklaşık $10 \mathrm{~nm}$ civarında boyuta sahip Ti(II) oksit nanoparçacıkların üretildiği görülmektedir. Elde edilen Ti (II) oksit nanoparçacıkların yapısal karakteristikleri, literatürde rapor edilen Ti(II) oksit nanoparçacıklara oldukça benzerdir [26]. Ayrıca, üretilen nanoparçacıkların AFM ile de karakterizasyonları gerçekleştirilmiştir. Düz (Au (111)) taban malzeme üzerine dökülen nanoparçacıklar, topografik görüntüleri alınarak karakterize edilmiştir. Şekil 2'de çalışmada kullanılan Ti(II) oksit nanoparçacığın pürüzlülük ölçümlerine ait bir görüntü verilmiştir. AFM pürüzlülük analizleri, ortalama $6.9 \mathrm{~nm}$ civarında bir sonuç vermiştir. Bu durum üretilen Ti(II) oksit nanoparçacıkların $10 \mathrm{~nm}$ 'den ufak olduğuna dair bir kanıt olarak gösterilebilir. Ayrıca, Ti(II) oksit nanoparçacıkların yüzeye dökümlerinden elde edilen AFM ölçümlerinde, pürüzlülük değerine ait standart sapmanın $\pm 0.874 \mathrm{~nm}$ olduğu belirlenmiştir. Bu sonuç, nanoparçacık büyüklüğünün nispeten uniform olduğunu da göstermektedir.
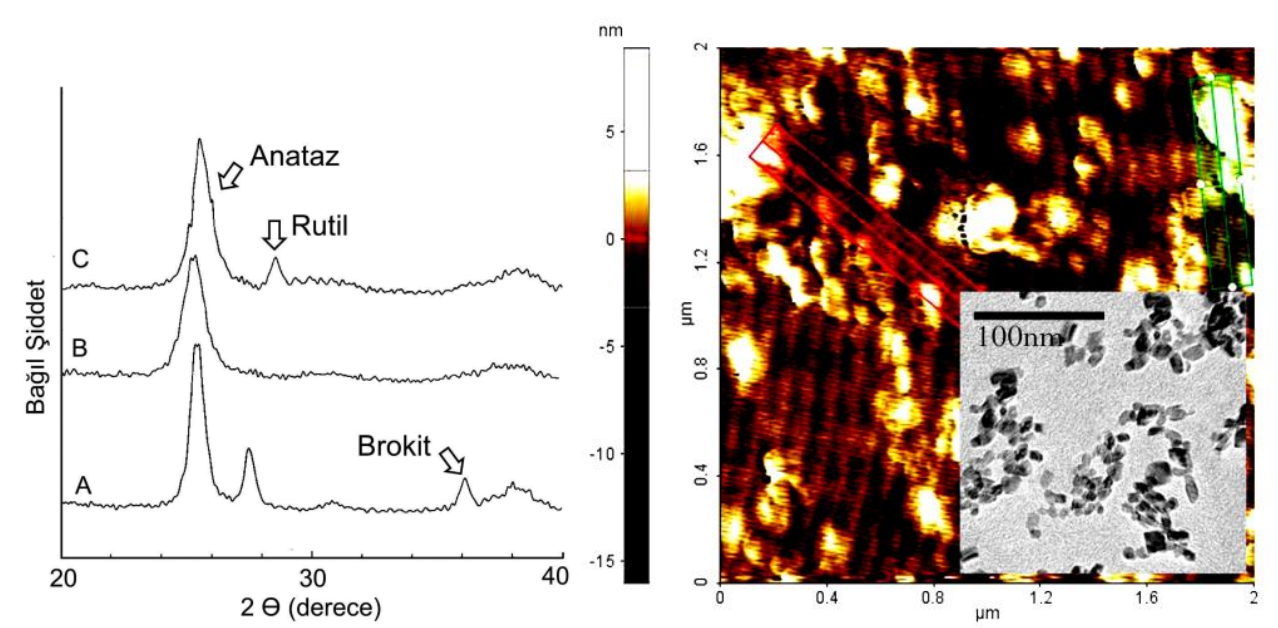

Şekil 1. A) Üretilen Ti (II) oksit nanoparçacıklara ait XRD sonuçları B) RPV ortalama $6.9 \mathrm{~nm}$ olan Ti(II) oksit nanoparçackklarının AFM ve TEM görüntüleri

\section{B. GMA-co-EGDMA ve Ti(II) Oksit Yüklü Mikrokürelerin Karakterizasyonu}

Elde edilen GMA-co-EGDMA mikrokürelerin (Şekil 3) kimyasal olarak karakterizasyonu kızılötesi spektrofotometresi (FTIR) kullanılarak gerçekleştirilmiştir. FTIR spektrumları, GMA-co-EGDMA yapısına ait temel pikleri sergilemektedir. FTIR spektrumunda 2990 ve $2950 \mathrm{~cm}^{-1}(\mathrm{vC}-\mathrm{H}) 1730 \mathrm{~cm}^{-1}(\mathrm{vC} \cdot \mathrm{O}), 1390$ ve 1450 $\mathrm{cm}^{-1}$ ( $\delta \mathrm{C}-\mathrm{H}$ asimetrik ve $\delta \mathrm{C}-\mathrm{H}$ simetrik), ve $1150 \mathrm{~cm}^{-1}(\mathrm{vC}-\mathrm{O}-\mathrm{C})$ karakteristik pikleri elde edilmiştir. Ti(II) oksit nanoparçacık ilave edilmiş mikrokürelerde ise $1390 \mathrm{~cm}^{-1}$ 'deki pikte görülen genişleme (vTi-OH) ve 590 $\mathrm{cm}^{-1}$, de elde edilen zayıf pik ( $\left.\delta \mathrm{Ti}-\mathrm{O}-\mathrm{O}\right)$, Ti(II) oksit nanoparçacıkların yapıya dâhil edildiğini göstermektedir. 


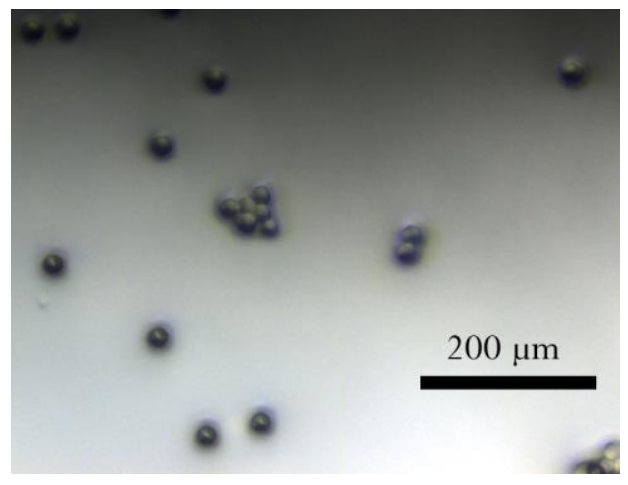

Şekil 3. GMA-co-EGDMA mikrokürelerin optik mikroskop görüntüsü

Ayrıca, polimere yüklenmiş Ti(II) oksit yapılarına ait AFM görüntüleri de alınmıştır (Şekil 4). Mikrokürelerde hapsedilmiş nanoparçacıklar, AFM ile daha net bir şekilde görülebilmektedir. Polimere ait gözenekli yapının yanı sıra, pürüzlülük analizi sonucu da belirlenen (yaklaşık $40 \mathrm{~nm}$ RMS) oluşumlar, yapıda tutuklanmış Ti(II) oksit kümelerinin bir göstergesidir. Boş mikroküreler için Rpv (tepeden-çukura) pürüzlülük değerleri çok yüksek iken, RMS pürüzlülük değerleri 4-6 nm civarında değişmektedir. Ti(II) oksit tutuklanmış polimerlerde RMS değerindeki artış, yapıya ilave edilmiş olan Ti(II) oksit nanoparçacıklar nedeniyledir.

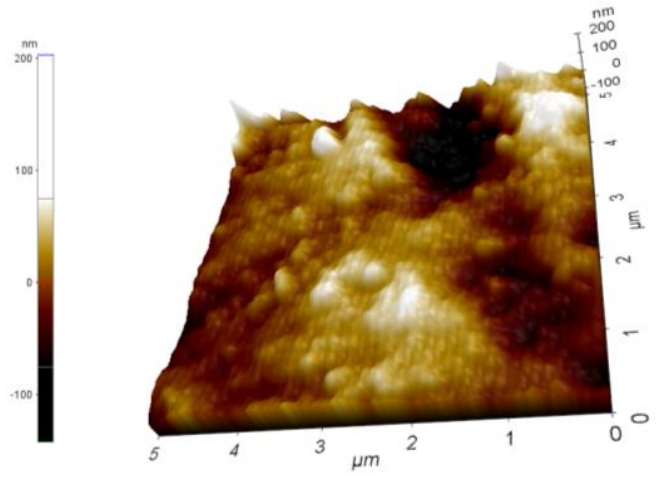

Şekil 3. GMA-co-EGDMA hidrojeline hapsedilmiş Ti (II) oksit'lere ait AFM görüntüsü. Ti (II) oksit birikintileri küçük çıkıntılar halinde görülmektedir. Arka plan, nispeten gözenekli GMA/EGDMA yapısıdır

\section{Fotokataliözlerin Sulu Ortamdan Reaktif-Tekstil Boyalarının Giderilmesinde Kullanımı}

Çalışmada kullanılan boyalar için (Tablo 1) pH etkisi, fotokatalizör miktarı gibi parametreler, her bir boya için ayrı ayrı incelenmiştir. Başlangıç pH'ının katalitik bozunmaya etkisinin belirlenmesi için 80 ppm'lik boya çözeltilerinin pH'ı derişik $\mathrm{NaOH}$ ve $\mathrm{HCl}$ ilave edilerek 4.0 ila 12.0 arasında ayarlanmıştır. 60 dakika UV 1şık altında karıştırılarak ölçülen renk giderimi değerleri grafiğe geçirilerek pH'ın fotokatalitik tepkimeye etkisi incelenmiştir. Tüm boyalar için belirlenen optimim giderim $\mathrm{pH}$ '1 Tablo 1'de verilmiştir. Çözelti pH'1, fotokatalizörün yüzey yüküne etki etmesi nedeniyle yarı iletken parçacık yüzeyinde gerçekleşen reaksiyonlarda önemli bir parametredir. Çalışmada kullanılan metilen turuncusu hariç, diğer boyalar için yüksek pH'ta katalizörün negatif olarak yüklenmiş olan aktif bölge sayısının artması ile performans bir miktar artmaktadır. 
Tablo 1. Çalışmada kullanılan boyalar, yapıları, maksimum soğurum yaptığı dalga boyları ve optimum giderim pH'ları

\begin{tabular}{|c|c|c|c|}
\hline Boya & Yapı & $\underset{(\mathbf{n m})}{\operatorname{Max} \text { Abs. }}$ & $\underset{\text { giderim pH' }}{\text { Optimum }}$ \\
\hline $\begin{array}{c}\text { Asit mavisi } \\
29\end{array}$ & & $602 \mathrm{~nm}$ & 8.0 \\
\hline $\begin{array}{c}\text { Alizarin } \\
\text { Kırmızısı S }\end{array}$ & & $430 \mathrm{~nm}$ & 8.0 \\
\hline $\begin{array}{c}\text { Kongo } \\
\text { kırmızısı }\end{array}$ & & $510 \mathrm{~nm}$ & 6.0 \\
\hline $\begin{array}{c}\text { Metil } \\
\text { turuncusu }\end{array}$ & & $463 \mathrm{~nm}$ & 3.5 \\
\hline
\end{tabular}

Üretilen polimer mikroküreye hapsedilmiş Ti(II) oksit katalizörün farklı boyalardaki performansını karşılaştırabilmek için kullanılacak katalizör miktarının belirlenmesi gerekmiş̧ir. Çalışmada kullanılacak fotokatalizör miktarını belirlemek için $50 \mathrm{ppm}$ ila 200 ppm arasındaki derişimlerde ve optimum pH değerinde hazırlanmış boyalar kullanılarak farklı katalizör miktarlarında $(\mathrm{m} / \mathrm{v}) 60$ dakika süresince UV 1 şı altında fotokataliz tepkimesinin gerçekleşmesi sağlanmıştır. Ancak, belirli bir derişimin üzerinde Ti(II) oksit'nin ortama ilave edilmesi sonucu gerçekleşen opaklık, katalitik tepkime için gerekli olan UV 1ş̧ı̆ın ortama girmesini engellediğinden \% Renk Giderimi değerinde düşüşe neden olmaktadır. 10 ppm ve üzerinde bu azalma etkileri görülmektedir. Katalitik bozunma işleminde Ti(II) oksit'nin doğrudan kullanılmasında, Ti(II) oksit'nin disperse edilmesi de çok önemlidir. Sürekli karıştırma durumunda, dispersiyonun nasıl olduğu konusunda herhangi bir çalı̧̧ma yapılamamıştır. Ancak, belirtilen derişimlerde bile, çözeltinin karıştırılmaması durumunda belirli bir miktar çökelme söz konusu olmaktadır. Ayrıca, çok düşük derişimlerde bile nano Ti(II) oksit süspansiyonu hızla opaklaşmaya başlamaktadır. GMA-co-EGDMA mikrokürelerin içerisine immobilize edilmiş olan Ti(II) oksit (Poli-Ti) kullanılarak fotokatalitik bozunmaya pH'ın etkisi incelenmiştir. Yine benzer şekilde, hazırlanan 80 ppm'lik boya çözeltilerinin pH'ı derişik $\mathrm{NaOH}$ ve $\mathrm{HCl}$ ilave edilerek bu kez 6.0 ila 10.0 arasında ayarlanmıştır. pH etkisinin doğrudan Ti(II) oksit kullanımına benzer sonuç verdiği görülmüştür.

Aynı katalizör miktarı ve optimum pH’ta yalnızca Ti(II) oksit nanoparçacık ile Poli-Ti kullanıldığı durumda zamana bağlı renk giderimi karşılaştıııldığında, Poli-Ti ile reaksiyon hızının düştüğü, daha düşük boya yüklemelerinde bile $\% 100$ boya giderimi için sürenin oda sıcaklığında 150 dakikayı aştığı gözlenmiştir. Belirli süre, boya yükü ve katalizör yükü için, optimum koşullarda Ti(II) oksidin tek başına kullanıldığı durumda giderim daha fazla olmuştur. Burada GMA-co-EGDMA polimer kürelerinin Ti(II) oksit yüklüyken ve yüklü değilken opak bir görünüme sahip olması ve UV ışığı nispeten az geçirmesi katalitik tepkimenin yavaşlamasına neden olabilir.

$\mathrm{Bu}$ durum, herhangi bir taşıyıcı kullanılarak fotokatalitik tepkimenin gerçekleştirildiği durumlarda ortaya çıkmaktadır. Taşıyıcının UV bölgede opaklığı nedeniyle performans düşüşü gözlenmesi doğaldır. Ancak burada, uygulamada kolay filtrelenebilme özelliklerinin de dikkate alınması gerekir. Mikrokürelere hapsedilmiş Ti (II) oksit nanoparçacıklar, çok daha basit bir çöktürme ile veya filtreleme teknikleri ile sulu ortamdan uzaklaştırılabilmektedir. Bu nedenle, kinetik çalışma verileri göz önüne alınırken, uygulanabilirlik de dikkate alınmalıdır. 
Tüm boya gruplarında, immobilize edilmiş olan Ti (II) oksit nanoparçacık, immobilize edilmemiş Ti (II) oksit nanoparçacığa oranla daha düşük bir renk giderimi sağlamıştır. Bunun nedeni, GMA/EGDMA mikro kürelerinin, belirli miktar UV ışığı absorplayarak, Ti (II) oksit parçacığın 1şık alan yüzey oranını azaltması ve bu nedenle de tepkime hızının azalması olabilir.

GMA-co-EGDMA/Ti (II) oksit katalizöründe peroksit kullanımının renk giderimine etkisi incelendiğinde $5 \mathrm{mM} / \mathrm{L}$ derişimdeki $\mathrm{H}_{2} \mathrm{O}_{2}$ 'nin çoğu boya grubu için yaklaşık optimum değer olduğu belirlenmiştir. Çalışılan boyaların asidik karakterli olması nedeniyle, optimum $\mathrm{H}_{2} \mathrm{O}_{2}$ derişimieri de yaklaşık olarak aynı olmuştur. Genel olarak $\mathrm{H}_{2} \mathrm{O}_{2}$ derişiminin artması performansa kısıtlı miktarda etki etmektedir. Yüksek $\mathrm{H}_{2} \mathrm{O}_{2}$ derişimi, gerek katalizöre gerek taşıyıcıya verdiği zarar nedeniyle performansı artırmaya devam etmemektedir [2].

Tablo 2'de tüm boyalar için optimum koşullarda, aynı miktarda katalizör ilavesi ile elde edilen giderim verimleri listelenmiştir. Reaksiyon hızı düşse de, Ti(II) oksit yüklü mikrokürelerin başarı ile kullanıldı̆̆ söylenebilir.

Tablo 2. Çalışmada kullanılan boyalar için $\left(20 \mathrm{ppm}\right.$ boya, 60 dakika, $\left.25^{\circ} \mathrm{C}\right)$, aynı miktarda katalizör kullanılarak elde edilen renk giderme verimleri

\begin{tabular}{lll}
\hline Boya & $\begin{array}{l}\mathbf{1 0} \mathbf{~ p p m ~ T i} \text { (II) } \\
\text { oksit }\end{array}$ & $\begin{array}{l}\mathbf{1 0} \mathbf{~ p p m ~ P o l i / T i} \text { (II) } \\
\text { oksit }\end{array}$ \\
\hline Alizarin Kırmızıs1 S & $\% 91.7$ & $\% 69.8$ \\
Kongo Kırmızıs1 & $\% 92.5$ & $\% 71.2$ \\
Metilen Turuncusu & $\% 81.3$ & $\% 64.1$ \\
Asit Mavisi & $\% 78.2$ & $\% 66.1$ \\
\hline
\end{tabular}

Çalışma sonuçları şu şekilde özetlenebilir:

Çalışmada kullanılan Alizarin kırmızısı S, Kongo kırmızısı, Asit mavisi ve metil turuncusu (asidik boyalar) ile elde edilen 20 ppm boya için 60 dakika sonrası renk giderme verimi Tablo 2'de verilmiştir. Tüm boyalar için optimum $\mathrm{pH}$ değerleri metil turuncusu hariç nötr veya bazik ortamlardadır (Tablo 1 ). $\mathrm{H}_{2} \mathrm{O}_{2}$ derişimleri, tüm boyalar için optimum $5 \mathrm{mM} / \mathrm{L}$ civarındadır. UV ışıma altında bile $25^{\circ} \mathrm{C}$ için fotokatalitik bozunma yavaş gerçekleşmektedir (>120 dakika). Bu hız, polimerik taşıyıcı kullanıldığı durumda daha da düşmektedir (>150 dakika). Tüm boyalar için, Ti(II) oksit'nin nanoparçacık halinde doğrudan dağıtılarak kullanılması sonucu renk giderim hızı daha yüksek olmaktadır. Tüm boyalar ve tüm katalizörler için, 1şık geçiriminin sağlandığı tüm durumlarda renk giderim verimi \%100'e ulaşmaktadır. Üretilen katalizörün ömrü oldukça yüksektir. 6 ay kadar sulu ortamda kalan GMA-co-EGDMA polimer kürecikleri kararlılığıını korumaktadır. Ancak Ti(II) oksit nanoparçacıkların taşıyıcı terk etmesi ile ilgili bir çalışma gerçekleştirilmemiştir.

\section{TEŞEKKÜR}

Bu çalışmaya esas olan verilerin elde edilmesinde Cumhuriyet Üniversitesi Çevre Mühendisliği Bölümü öğretim üyelerinden Dr. Bünyamin Karagözoğlu ve Dr. Fuat Özyonar'ın katkıları nedeniyle teşekkür ederim. Ayrıca, proje Cumhuriyet Üniversitesi Bilimsel Araştırma Projeleri Başkanlığınca M410 numaralı BAP projesi olarak desteklenmiştir.

\section{KAYNAKLAR}

[1] Borker, P., \& Salker A.V. (2006). Photocatalytic degradation of textile azo dye over $\mathrm{Ce}_{1}-\mathrm{xSn}_{\mathrm{x}} \mathrm{O}_{2}$ series. Materials Science and Engineering: B, 133(1): 55-60. 
[2] Konstantinou, I., \& Albanis, T. (2004). $\mathrm{T}_{\mathrm{i}} \mathrm{O}_{2}$-Assisted Photocatalytic Degradation of Azo Dyes in Aqueous Solution: Kinetic and Mechanistic Investigations: A Review. 49: 1-14.

[3] Ehrampoosh, H. M., Moussavi, G., Ghaneian, M. T. A. B., Ahmadian, M. (2011). Removal of methylene blue dye from textile simulated sample using tubular reactor and $\mathrm{TiO}_{2} / \mathrm{UV}-\mathrm{C}$ photocatalytic process. 8: 35 40 .

[4] Prado, A.G.S., Bolzon, L.B., Pedroso, C.P., Moura, A.O., Costa, L.L. (2008). $\mathrm{Nb}_{2} \mathrm{O}_{5}$ as efficient and recyclable photocatalyst for indigo carmine degradation. Applied Catalysis B: Environmental, 82(3): 219224.

[5] Akpan, U.G., \& Hameed, B.H. (2009). Parameters affecting the photocatalytic degradation of dyes using TiO2-based photocatalysts: a review. J Hazard Mater, 170(2-3): 520-529.

[6] Malato, S., Fernández-Ibáñez, P., Maldonado, M.I., Blanco, J., Gernjak, W. (2009). Decontamination and disinfection of water by solar photocatalysis: Recent overview and trends. Catalysis Today, 147(1): 1-59.

[7] Sun, Z., Chen, Y., Yang, Q., Ke, Y., Yuan, J. (2002). Photocatalytic degradation of a cationic azo dye by TiO2/bentonite nanocomposite. Journal of Photochemistry and Photobiology A: Chemistry, 149(1): 169174.

[8] Uğurlu, M. (2009). Adsorption of a textile dye onto activated sepiolite. Microporous and Mesoporous Materials, 119(1): 276-283.

[9] Kun, R., Mogyorósi, K., Dékány, I. (2006). Synthesis and structural and photocatalytic properties of $\mathrm{TiO}_{2} /$ montmorillonite nanocomposites. Applied Clay Science, 32(1): 99-110.

[10] Fukahori, S., Ichiura, H., Kitaoka, T., Tanaka, H. (2003). Photocatalytic decomposition of bisphenol A in water using composite TiO2-zeolite sheets prepared by a papermaking technique. Environ Sci Technol, 37(5): 1048-1051.

[11] Chong, M.N., Jin, B., Chow, C.W, Saint, C. (2010). Recent developments in photocatalytic water treatment technology: a review. Water Res, 44(10): 2997-3027.

[12] Choi, H., Stathatos, E., Dionysiou, D.D. (2007). Photocatalytic $\mathrm{TiO}_{2}$ films and membranes for the development of efficient wastewater treatment and reuse systems. Desalination, 202(1): 199-206.

[13] Molinari, R., Pirillo, F., Falco, M., Loddo,V., Palmisano, L. (2004). Photocatalytic degradation of dyes by using a membrane reactor. Chemical Engineering and Processing: Process Intensification, 43(9): 11031114 .

[14] Yu, Y., Yu, J.C., Yu, J.-G., Kwok, Y.-C., Che, Y.-K., Zhao, J.-C., Ding, L., Ge, W.-K., Wong, P.-K. (2005). Enhancement of photocatalytic activity of mesoporous $\mathrm{TiO}_{2}$ by using carbon nanotubes. Applied Catalysis A: General, 289(2): 186-196.

[15] Vinodgopal, K., Wynkoop, D.E, Kamat., P.V. (1996). Environmental Photochemistry on Semiconductor Surfaces: Photosensitized Degradation of a Textile Azo Dye, Acid Orange 7, on $\mathrm{TiO}_{2}$ Particles Using Visible Light. Environmental Science \& Technology, 30(5): 1660-1666.

[16] Ni, M., Leung, M.K.H., Leung, D., Sumathy, K. (2007). A Review and Recent Developments in Photocatalytic Water-Splitting Using $\mathrm{TiO}_{2}$ for Hydrogen Production.11: 401-425.

[17] Litter, M.I. (1999). Heterogeneous photocatalysis: Transition metal ions in photocatalytic systems. Applied Catalysis B: Environmental, 23(2): 89-114.

[18] Gelover, S., Mondragón, P., Jiménez, A. (2004). Titanium dioxide sol-gel deposited over glass and its application as a photocatalyst for water decontamination. Journal of Photochemistry and Photobiology A: Chemistry, 165(1): 241-246.

[19] Carpio, E., Zuñiga, P., Ponce, S., Solis, J., Rodríguez, J., Estrada, W. (2005). Photocatalytic degradation of phenol using $\mathrm{TiO}_{2}$ nanocrystals supported on activated carbon. 228: 293-298. 
[20] Shironita, S., Mori, K., Shimizu, T., Ohmichi, T., Mimura, N., Yamashita, H. (2008). Preparation of nanosized platinum metal catalyst using photo-assisted deposition method on mesoporous silica including single-site photocatalyst. Applied Surface Science, 254(23): 7604-7607.

[21] Damodar, R.A., \& Swaminathan, T., (2008). Performance evaluation of a continuous flow immobilized rotating tube photocatalytic reactor (IRTPR) immobilized with $\mathrm{TiO}_{2}$ catalyst for azo dye degradation. Chemical Engineering Journal, 144(1): 59-66.

[22] Shan, A.Y., Ghazi, T.I.M., Rashid, S.A. (2010). Immobilisation of titanium dioxide onto supporting materials in heterogeneous photocatalysis: A review. Applied Catalysis A: General, 389(1): 1-8.

[23] Li, Y., \& Kim, S.-J. (2005). Synthesis and Characterization of Nano titania Particles Embedded in Mesoporous Silica with Both High Photocatalytic Activity and Adsorption Capability. The Journal of Physical Chemistry B, 109(25): 12309-12315.

[24] Fabiyi, M., \& Skelton, R.L. (2000). Photocatalytic Mineralisation of Methylene Blue using Buoyant TiO2Coated Polystyrene Beads. 132: 121-128.

[25] Mahshid, S., Askari, M., Sasani Ghamsari, M. (2007). Synthesis of TiO2 Nanoparticles by Hydrolysis and Peptization of Titanium Isopropoxide Solution. 189: 296-300.

[26] Xiong, Z., Wu, H., Zhang, L., Gu, Y., Zhao X.S. (2014). Synthesis of $\mathrm{TiO}_{2}$ with controllable ratio of anatase to rutile. Journal of Materials Chemistry A, 2(24): 9291-9297. 